\title{
UNDERSTANDING AND OVERCOMING PRAGMATIC FAILURE IN \\ INTERCULTURAL COMMUNICATION: \\ FROM FOCUS ON SPEAKERS TO FOCUS ON HEARERS
}

\author{
Manuel Padilla Cruz
}

\begin{abstract}
For learners to communicate efficiently in the L2, they must avoid pragmatic failure. In many cases, teachers' praxis centres on the learner's performance in the L2 or his role as a speaker, which neglects the importance of his role as interpreter of utterances. Assuming that, as hearers, learners also have a responsibility to avoid pragmatic failure, this paper endorses the relevance-theoretic view of communication, its explanation about why misunderstandings arise, and the belief that the learner's sophistication in understanding is not the same as that of a native. Therefore, it argues that learners must be taught to be cautious optimistic hearers. As a result, learners will be able to reject interpretations of utterances, which, due to the linguistic or cultural incompetence of their native or non-native interlocutors in the L2 system, they are led to regard as relevant enough although their interlocutors may have expected them to arrive at a different interpretation.
\end{abstract}




\section{Introduction}

One of the major aims of Second Language Teaching is for the L2 learner to achieve efficient communication that conforms to native standards. However, one of the factors that can impede such communication is pragmatic failure (Thomas 1983). Although in some cases pragmatic failure lacks serious consequences, and, on the contrary, results in rather funny and anecdotal misunderstandings, in other cases it has more dramatic repercussions by causing misunderstandings that may result in puzzlement, surprise, astonishment, frustration, embarrassment or anger. In extreme cases, it may even produce interactive conflict, cultural friction, communication breakdown, unfair and unjustified attribution of personality traits with subsequent negative labelling and stereotypes, or contribute to the perpetuation of discrimination as a consequence of very different interactive norms across speech communities (Thomas 1983; Beebe and Takahashi 1989; Kasanga 2001; Kasanga and Lwanga-Lumu 2007). In fact, deviations from the expected or usual communicative practices in a community or sociocultural group are judged differently depending on the degree of error or flaw perceived (Riley 2006: 314).

Over the past decades, pragmatic failure has attracted due attention from many researchers, who have examined performance by L2 learners or non-natives of many different languages and cultural backgrounds in an overwhelmingly rich variety of speech acts which include, among many others:

- greetings (e.g. Jaworski 1994),

- $\quad$ apologies (e.g. Olshtain 1983; Blum-Kulka and Levenston 1987; García 1989; Harlow 1990; Kasanga and Lwanga-Lumu 2007),

- compliments (e.g. Nelson et al. 1996; Nelson et al. 1996),

- refusals (e.g. Beebe et al. 1990; Kwon 2004), 
- $\quad$ requests (e.g. Blum-Kulka 1988; Blum-Kulka and Levenston 1987; Færch and Kasper 1989; Harlow 1990; Kasanga 1998; Lwanga-Lumu 2002), or

- $\quad$ the expression of gratitude (e.g. Harlow 1990; Eisenstein and Bodman 1993).

Researchers have also examined non-natives speakers' behaviour in many different interactive contexts (e.g. Kakavá 1993; Hale 1996; Pennock and Suau 1998; Arent 2000; Kasanga 2001). The majority of such cross-cultural investigations, however, centres on the learners' or non-natives' (inappropriate) performance as speakers and stresses the effects that their linguistic behaviour or conversational style may have upon their native interlocutors. ${ }^{1}$

Regarding hearers, what can be found in these works are brief comments and reflections on the hearers' possible or actual reactions to linguistic behaviours or conversational styles that differ from what they would expect from a certain context in their culture or community of practice. $^{2}$ It seems that the responsibility for not using the L2 appropriately and making unfortunate mistakes causing undesired misunderstandings is almost exclusively attributed to learners or non-native speakers — an attribution that greatly simplifies the complexity of communication and under-represents hearer's role in it. However, pragmatic failure also depends on hearers, regardless of whether they are native or non-native, as they are the interpreters of the utterances. In effect, the very definition of pragmatic failure proposed by Thomas (1983: 93) explicitly states that it lies in an inability to understand what speakers say. By having excessively focused on learners' role as speakers and producers of utterances, researchers have most likely neglected the importance of learners' role as hearers and the importance that understanding (correctly) has in communication (Garcés Conejos and Bou Franch 2002). If one of the aims of L2 teaching is to provide learners with the necessary knowledge that makes them communicatively competent in the L2 (Canale and Swain 1980;

\footnotetext{
${ }^{1}$ In this paper the terms 'speaker' and 'hearer' will be taken to refer to both native and non-native speakers and hearers.

${ }^{2}$ Wenger describes a community of practice as a loosely defined social group engaged in a particular task and sharing a "[...] repertoire of negotiable resources accumulated over time" (1998: 76).
} 
Canale 1983; Bachman 1990; Celce-Murcia et al. 1995), their role as hearers should not be overlooked or dismissed. In fact, it is extremely important that teachers dedicate much effort to improve hearers' interpretive skills. L2 teachers should not forget that their students, in addition to becoming competent speakers, must also become competent hearers and, as such, they must learn how to interpret utterances correctly, understand why they interpret them in one specific way and solve interpretive problems. This skill will certainly increase learners' awareness of communication risks and help them overcome some of the problems that appear in intercultural exchanges.

This paper does not centre on learners' performance as speakers, but on their performance as hearers. It reflects on the way in which hearers can overcome conversational misunderstandings arising from ambiguous or pragmatically ambivalent utterances, utterances that are not adjusted to sociocultural interactive norms or principles operating in the L2 culture, or from their own insufficient or inadequate processing. This paper argues that one of the interpretive strategies available to hearers, which Sperber (1994) labels cautious optimism, can significantly help non-native hearers overcome conversational misunderstandings and pragmatic failures when processing utterances that their native or non-native interlocutors would have expected them to assign a particular interpretation. This strategy consists of a competent attribution of beliefs and intentions, which enables hearers to reject previously reached interpretations of utterances and look for alternative, more plausible ones. It is a more sophisticated strategy than the so-called nä̈ve optimism (Sperber 1994), which leads hearers to accept the interpretations they reach without further questioning and to believe those interpretations to be the ones intended by their interlocutors.

This paper begins by briefly explaining pragmatic failure and its two types and reviewing a classification of hearer's misunderstandings in Section 2 (Yus Ramos 1999a, 1999b). Section 3 addresses the origins and causes of pragmatic failure frequently pointed out in the literature 
on the topic. Since in order to correctly account for pragmatic failure it is also necessary to be aware of processing factors from which it originates, Section 3 adopts the relevance-theoretic description of communication (Sperber and Wilson 1986, 1995; Wilson and Sperber 2004) to discuss why hearers arrive at an interpretation that may differ from the one the speaker intended to communicate and the cognitive strategy which may be responsible. Section 4 deals with different proposals aimed at avoiding pragmatic failure. Assuming that the majority of such proposals are intended to improve learners' communicative competence as speakers and that few proposals have aimed at developing their comprehension skills, Section 5 argues that teachers' concern must focus on learners' role as hearers and the development of cautious optimism, a cognitive strategy that will help them avoid pragmatic failure and misunderstandings arising from accidental relevance and accidental irrelevance of utterances (Wilson 1999).

\section{Pragmatic failure and misunderstandings: definition and types}

Misunderstandings pervade intra-cultural communication between members of different cultural groups or communities of practice in many contexts (e.g. Tannen 1990; Coupland et al. 1992). In cross-cultural or intercultural communication, understood as communication between individuals belonging to (rather) different cultural groups and languages, misunderstandings are even more likely to occur because hearers may fail to understand what their non-native interlocutors intend to communicate with an utterance in a specific communicative circumstance or do not capture the intended pragmatic force of their utterances. When this happens, interlocutors experience a pragmatic failure, which Thomas defines as "[...] the inability to understand what is meant by what is said" (1983: 93). 
Although the term seems to have been restricted to intercultural communication and, typically, to interaction between native and non-native speakers of a language or learners of a non-native language, it must be understood as referring to misunderstandings arising " $[\ldots]$ whenever two speakers fail to understand each other's intentions" (Blum-Kulka and Olshtain 1986: 166).

Since the coinage of the term, two types of such failure are normally distinguished according to Leech's (1983) differentiation between pragmalinguistic and sociopragmatic aspects of language usage: pragmalinguistic failure and sociopragmatic failure. The former type arises when non-native speakers or L2 learners inadequately transfer linguistic strategies from their L1 to the L2, when they repeatedly resort to certain linguistic strategies and overgeneralise their usage or when they alter the order of strategies used to perform some speech act sequences or sets. Pragmalinguistic failure may also arise when non-natives do not identify or express meaning correctly or use wrong suprasegmental/prosodic features (Thomas 1983; Riley 1989, 2006; Olshtain and Cohen 1990; Tran 2006). The literature offers many examples of this type of pragmatic failure. Thus, Olshtain and Cohen (1990) comment that the absence of intensifiers such as very, deeply or really in apologies by Israeli learners of English led their American interlocutors to perceive their apologies as insincere, formulaic or not very genuine. Han (1992) reports that Korean learners of English interpreted really? as a request for reassurance or repetition rather than as a compliment acceptance. Regarding compliments, Nelson et al. (1996) and Nelson et al. (1996) have found out that Syrian Arabic learners of English do not normally respond to compliments by simply accepting them with routines such as thank you, but with much more elaborate formulae, while Egyptian learners of English resort to innovative and creative comparisons or metaphors when paying compliments (1), which may sound somewhat puzzling or weird to their American complimentees:

(1) You look like a bridegroom today! 
Finally, Arent (2000) explains that a question such as (2) intended as a sort of preliminary greeting or token of phatic communion at the beginning of a bargaining exchange is understood by many non-Arabs as an invasive request for personal information:

(2) Where are you from?

Sociopragmatic failure, on the contrary, originates when non-native speakers unknowingly abide by their L1 rules of speaking and their communicative behaviour is therefore influenced by their sociocultural competence in the L1. This in many cases prevents them from correctly identifying social situations (Takahashi and Beebe 1987; Riley 1989, 2006; Wolfson 1989; Beebe et al. 1990). In fact, L2 learners sometimes assume as universal the social norms governing their own behaviour in specific circumstances and apply them directly to interaction in their L2 (Olshtain and Cohen 1989; Wolfson 1989; Tran 2006). Sociopragmatic failures reveal cross-linguistic influences on the learners' L2 verbal behaviour and comprehension (Takahashi and Beebe 1993), for the learners' knowledge of their mother tongue - or even a language other than their L2 - affects their linguistic production and understanding (Kasper 1992; Kasper and Blum-Kulka 1993).

The literature also offers plenty of examples of sociopragmatic failure. Thus, Hickey (1991) shows that Britons often interpret (too) personal compliments like those in $(3,4)$ by Spaniards as embarrassing, ironic or insincere:

(3) ¡Qué buena persona eres! [What a good person you are!]

(4) ¡Qué puntual eres! [How punctual you are!]

Kakavá (1993) explains that different conversational styles are responsible of many misperceptions between Greeks, Greek Americans and Americans when facing arguments in academic contexts. Reynolds (1995) comments that his Finnish students were able to tolerate silence and taciturnity better than their British counterparts, so the former were surprised when their British mates engaged in small talk and regarded them as quite loquacious. Chen 
(1993) shows that the Chinese tendency to reject compliments is motivated by Leech's (1983) modesty maxim and creates many misunderstandings when Chinese learners of English interact with Americans, for the latter tend to accept compliments as a result of the operation of Leech's (1983) agreement maxim in their culture. Likewise, Nelson et al. (1996) point out that because of their underlying sociocultural principles, some Egyptian learners of English offered the object praised in a compliment to the person paying the compliment, and did not simply accept the compliments made by their English interlocutors. ${ }^{3}$

Pragmatic or interactive norms/principles are subject to intercultural variation and may not be shared by individuals belonging to different cultures or communities of practice. When sociopragmatic failure occurs, the native interlocutor is not facing an overt, intended violation of those norms/principles with the aim of provoking a particular effect - e.g. implicatures but a covert, unintended violation that might have a whole range of consequences, as the native can think that the learner "[...] fails to live up to his [...] expectations in terms of appropriate adherence to regulative maxims" (Blum-Kulka and Olshtain 1986: 168).

In addition to misunderstandings arising as a result of learners' incompetence as speakers or their unawareness of interactive norms/principles operative in the L2 culture, there are also misunderstandings arising from an incorrect processing of utterances on the part of hearers, which can also cause pragmatic failure. Brown (1995: 34) mentions that on some occasions, apart from not listening to or hearing what speakers say, hearers can hear what their interlocutors say but be so engrossed in the processing of (a) previous utterance(s) that they cannot process other subsequent utterance(s) or understand some part or the whole of it/them.

\footnotetext{
${ }^{3}$ Decisions about whether specific examples of pragmatic failure are pragmalinguistic or sociopragmatic failures may be difficult to make, for both dimensions are inter-related (Thomas 1983; Kasper 1992). Examples (3) and (4) may be regarded as pragmalinguistic failures inasmuch as the speakers select strategies that may lead their interlocutors to interpretations differing from the intended ones. However, they are sociopragmatic failures insofar as the speakers have decided whether or not to compliment their interlocutors, and what the targets of their compliments are. Compliment responses by Egyptian learners might be a pragmalinguistic failure if these learners understood their interlocutors' compliments as requests for goods or information. However, since they understand their compliments as such, there is sociopragmatic failure as long as their responses are motivated by underlying sociocultural principles.
} 
On other occasions, hearers do understand the words of an utterance correctly, but they are unable to grasp some of its nuances or implicit meanings in a specific context or produce an appropriate response to it, perhaps because they need more information.

Working within the relevance-theoretic approach to communication (Sperber and Wilson 1986, 1995), Yus Ramos (1999a, 1999b) shows that hearers may encounter different problems when processing utterances, which may lead to misunderstandings at both the explicit and implicit level:

A) Misunderstandings at the explicit level:

i) Non-understanding, which happens when a hearer cannot find any plausible interpretation of his interlocutor's utterance because of noise in the communicative channel, the speaker's bad pronunciation, strong accent, deficient command of the language or usage of very specialised jargons or metalanguages. This type of misunderstanding would be illustrated by a student who cannot understand his teacher when he resorts to very specific and technical metalanguage to explain some notions in communication:

(5) The hearer must embed the lower-level explicature of the utterance under the higher-level explicature.

ii) Puzzled understanding, which occurs when the hearer fully understands the proposition expressed by an utterance (6) but, when enriching its logical form in order to obtain its higher-level explicature referring to the speaker's attitude, the saliency of a contextual assumption (7) leads him to misinterpret the speaker's attitude towards the proposition expressed and understand the utterance in a different way from the one intended by the speaker, ${ }^{4}$ e.g. as a criticism instead of as a compliment:

\footnotetext{
${ }^{4}$ In relevance-theoretic terms, the logical form of an utterance is a structured set of concepts that must be pragmatically enriched to make it fully propositional. When that operation is carried out, the hearer obtains the explicature of the utterance, or lower-level explicature, which can be embedded under an assumption schema referring to the speech act the speaker is performing or her attitude towards the content expressed. When that
} 
(6) You have bought a mini-skirt!

(7) Mary does not like very short skirts.

iii) Obtaining an alternative explicature different from the intended explicature. This originates when the hearer does not correctly disambiguate or assign reference to linguistic elements such as pronouns, indexicals, deictics or syntactic constituents because he has selected the wrong contextual information. This type of misunderstanding often happens to some Spanish learners of English, whose native language distinguishes between proximal, medial and distal deictics — aquí, ahí and allí. These learners may have problems when interpreting English there if they are not looking at their interlocutor or miss some pointing and, consequently, hesitate if the speaker meant a distant place or a not-so-distant place:

(8) A: Leave it there! [there meaning upon the table]

[The hearer leaves a glass on a shelf]

\section{A: Not there, but there!}

This misunderstanding can also be observed in conversations in which one of the speakers talks about several people, objects or animals and uses anaphoric pronouns to refer back to one or some of them. Hearers may assign wrong referents to those pronouns and not understand correctly their interlocutors:

(9) A: He is the one I love! [referring to a particular guy]

B: I didn't know you were in love with Peter!

A: Oh, no way, Susie! Bob is the one I love!

Finally, this misunderstanding can also be observed in many cases of intentionally or inadvertently syntactically-ambiguous utterances. The hearer may wrongly disambiguate them and come out with two equally plausible interpretations: 
(10)Flying planes can be dangerous [what is dangerous, planes that fly or the act of flying planes?]

iv) Turning an intended explicature into an unintended implicature, which arises when the hearer is not satisfied with the information conveyed by the proposition of an utterance and unnecessarily extends his interpretive context so as to search for additional contextual assumptions that lead him to obtain further implications. This would happen when the hearer finds the interpretation of an utterance such as (11) unsatisfactory as a phatic comment, expands his context with assumptions such as those in (12) and processes it as an unintended indirect request to close the room window:

(11)Oh, it is cold in here!

(12)a. It is cold in this room.

b. The window is open.

c. If the window was closed, the room would be warmer.

d. My interlocutor might want me to shut the window.

B) Misunderstandings at the implicit level:

i) Non-understanding, which occurs for the same reasons as the case of the first type of misunderstanding at the explicit level.

ii) Missing implicature, when the hearer lacks or is not aware of some essential contextual information and cannot therefore reach an intended implication. Thus, if a student who is very late to class is not aware of the exact time, he may miss the implicit content the teacher expected him to reach — "you are late to class" — when processing the following question by the teacher:

(13)Teacher: What time is it?

Student: 12.10.

iii) Alternative implicature, which arises because the hearer selects an erroneous contextual 
assumption that makes him draw a conclusion different from the one the speaker intended or expected. This misunderstanding happens in many cross-cultural exchanges where hearers use their cultural knowledge to process utterances produced by speakers of a different linguistic or cultural background. This is why the Americans referred to by Arent (2000) interpreted their Arab interlocutors' opening formula (3) as an intrusive question. This misunderstanding also occurs when hearers face slogans (14) or some (innovative) metaphors like those reported by Nelson et al. (1996), for whose processing they would lack assumptions that would have led them to a specific interpretation:

(14) Seville, the people's city. [A foreign student who visits Seville for the first time may wonder why it is being referred to in this way, as he may not know about the local policy to pedestrianise some districts]

iv) Turning an intended implicature into an unintended explicature, which occurs when the hearer stops his processing at the level of the proposition expressed by the utterance and does not expand his mental context so as to reach an intended implicature. As an example, consider a situation in which a student thinks that (15) is only a comment about the fact that he is late for class and does not recover the implicature (16):

You are late again today!

Don't be late again!

\section{Origins and causes of pragmatic failure}

When accounting for the origins and causes of pragmatic failure, researchers also seem to have exclusively limited their explanation to the role that the non-native speaker plays in intercultural communication. Accordingly, they seem to agree that pragmatic failure may stem 
from developmental and proficiency factors such as:

a) negative transfer of discourse stretches or linguistic strategies owing to a certain tendency to translate L1 linguistic strings directly into the L2,

b) undue overgeneralisations of L2 forms to inappropriate settings,

c) use of inadequate prosody,

d) anxiety to communicate as clearly as possible,

e) lack of cultural knowledge,

f) excessive and restrictive usage of textbook language, or

g) the limited language to which learners are exposed in the classroom (Thomas 1983; Tannen 1984; House 1990; Hurley 1992; Kasper 1992; Hale 1996).

Some available teaching materials have many shortcomings, for, even if they contain realistic linguistic input or aim at doing so, they are based on expert corpora or just the author(s)' intuitions. Hence, they offer samples of language which the authors regard as representative of authentic interaction, but do not duly address learners' possible deficiencies and the potential problems they may face when using the L2 in real contexts (Flowerdew 1997; Kasanga 2001). Textbook activities, furthermore, often contain an almost fictitious language and content and place students in situations in which they will hardly have to interact. The requirements that students must fulfil are almost exclusively linguistic, with practically no other extralinguistic side-effects than their teacher's or their classmates' (dis)approval.

Concerning hearers and interpretation, Kasper (1984) argues that activation of appropriate mental frames and schemata and also the selection of the adequate processing strategy (topdown or bottom-up) significantly determine successful understanding. Some schemata are culturally specific and may lead learners to interpret linguistic behaviour rather differently from how their native interlocutors would interpret it (Long 1989; Shakir and Farghal 1991). On the other hand, top-down processing seems adequate when communicative situations are 
conventionalised, hearers have rather firm expectations of what they are likely to face and they activate higher-order frames, whilst bottom-up processing is called for when hearers face ambiguous situations or lack schemata regarding specific (aspects of) interactive situations. If hearers are interacting in a rather conventionalised context and have to process a conventionalised speech act, the use of top-down processing can result in just one interpretation, but if the speech act they have to process is not conventionalised, that processing strategy may yield competing interpretations. In non-conventionalised contexts, on the contrary, bottom-up processing of conventionalised speech acts can result in a single interpretation, but if such processing strategy is applied to non-conventionalised speech acts, hearers may also arrive at different interpretations.

Understanding the origins and causes of pragmatic failure certainly requires an awareness of how hearers process utterances, which processing strategy they use and why they reach a particular interpretation (Sperber and Wilson 1986, 1995). Within cognitive pragmatics, relevance theory offers a model of interpretation that helps us understand why misunderstandings may arise.

\subsection{Relevance and communication}

Communication is a rather risky human activity: "While providing extraordinary benefits, communication is also a source of vulnerability to accidental or intentional misinformation" (Mascaro and Sperber 2009: 367). Utterances are public metarepresentations of the speaker's thoughts (Sperber 1994, 1995). For communication to succeed, the hearer must adequately process an utterance and obtain the interpretation that the speaker intends to communicate. But how can he do so? And why does a hearer select a specific interpretation and believe that it is the interpretation that his interlocutor intended to communicate? 
As intentional stimuli, utterances come with a guarantee of their relevance, i.e. a guarantee that their processing will yield cognitive effects. These originate when the information utterances communicate interacts with the old information the hearer possesses by strengthening or contradicting the old information or resulting in brand-new information that the hearer cannot otherwise obtain, i.e. contextual implications. But those cognitive effects require some cognitive effort that the hearer will have to invest in the processing of utterances. Utterances, nevertheless, generate firm expectations that their processing will be worth the effort that the hearer will have to invest, i.e. expectations of relevance.

When the hearer processes an utterance, he will search for the interpretation that yields the largest amount of cognitive effect for the lowest level of cognitive effort. In other words, the hearer will look for the interpretation that appears optimally relevant to him. He will do so following the interpretive path that provides him with the largest number of cognitive effects and requires the least processing effort: the relevance-theoretic comprehension procedure (Wilson 1999; Wilson and Sperber 2004). Once the hearer finds this interpretation, he may believe that it is indeed the interpretation that the speaker intended to communicate and consider it to be her informative intention. ${ }^{5}$ If he does not find an optimally relevant interpretation, or if the interpretation that he obtains does not correspond to the one the speaker intended to communicate, communication will fail and misunderstandings will be likely to arise.

\subsection{Nä̈ve optimism, (mis)interpretation and pragmatic failure}

The easiest and simplest cognitive strategy for processing utterances available to hearers is what Sperber (1994) labels nä̈ve optimism. A naïve and optimistic hearer presupposes that his

\footnotetext{
${ }^{5}$ According to Sperber and Wilson $(1986,1995)$, the speaker's informative intention is her intention to make manifest - i.e. to induce the hearer to entertain a mental representation - a certain set of assumptions.
} 
interlocutor is (i) benevolent, i.e. that she will not try to deceive him, and (ii) competent, i.e. that she adequately commands the grammatical rules and principles of usage of the language she speaks, will try to avoid misunderstandings and will provide him with relevant information (Sperber 1994; Mascaro and Sperber 2009).

If the speaker is indeed competent and benevolent, she will check the following:

a) that the information that she intends to communicate will in fact turn out optimally relevant to the hearer,

b) that the communicative strategy that she selects to transmit her message is appropriate, and

c) that the hearer will quickly and easily recover the intended interpretation instead of other possible candidates.

Consider an utterance such as (17):

(17) It is freezing in here!

In a context in which two individuals enter a room in which the windows are wide open on a winter morning, (17) may be a complaint about the temperature of the room, an indirect request to shut the window, an indirect request to shut the window and to turn a stove on, or merely a phatic comment about the temperature of the room. A competent and benevolent speaker may simply intend to communicate one of these possible interpretations to her hearer. If the hearer is naïve and optimistic, he will follow the relevance-theoretic comprehension procedure and may realise that the speaker has noticed the open window, seen that there is a stove in the room and hence believes that she intends for him to recover the requestinterpretation. Consequently, he will conclude that the speaker's informative intention is indeed this one, consider it optimally relevant and not think of other possible alternative interpretation. The existence of another possible interpretation would detract from optimal relevance because the hearer would have to assume the additional processing effort of testing 
it. This should not exclude, however, the possibility that a naïve and optimistic hearer may obtain an interpretation different from the one the speaker intended. For instance, if the hearer realises that the assumptions that (17) makes manifest are already manifest to himself and cannot obtain cognitive effects, the relevance-theoretic comprehension procedure may induce him to think that the speaker's intention was just to make a comment about the temperature of the room. In that case, he would interpret (17) as a phatic token, although the speaker's actual intention was not to communicate that interpretation. ${ }^{6}$ If this were to happen, the meaning that the hearer assigned to said utterance would not coincide with the one intended by the speaker. In communication there is no guarantee that hearers will always interpret utterances in the way speakers intend (Sperber and Wilson 1986, 1995; Wilson and Sperber 2004). Hearers contextualise the information they communicate by resorting to their general or global knowledge about other individuals, their behaviour, etc., their specific or local knowledge about more specific aspects of reality and behaviour and their interactive knowledge about interaction in specific contexts (Escandell Vidal 1996; Hayashi 1996). A great part of this knowledge is the result of having grown up within a sociocultural milieu or community of practice. Therefore, it is cultural and formed by metarepresentations shared by the members of the milieu (Sperber 1996). This knowledge conditions not only the way in which individuals behave verbally or otherwise, but also how they interpret utterances. Misunderstandings and pragmatic failures may sometimes arise as a consequence of a lack of cultural knowledge or differences in the contents of the cultural metarepresentations pertaining to different aspects of the individuals' social behaviour in specific circumstances. If intra-cultural communication is seen as communication between interlocutors who have in common most or many of their cultural metarepresentations, intercultural communication must be characterised as

\footnotetext{
${ }^{6}$ Žegarac (1998) claims that an utterance is assigned a phatic interpretation when the assumptions that it makes manifest are previously manifest to the hearer. Therefore, its relevance does not lie on the speaker's informative intention, but on her communicative intention, i.e. her intention to make manifest to the hearer that she has a particular informative intention.
} 
communication taking place between individuals who share only a few cultural metarepresentations referring to behaviour in specific circumstances (Žegarac 2009: 40). Accordingly, when the Finnish students reported by Reynolds (1995) preferred not to speak in situations in which Britons engaged in small talk, their behaviour was determined by the cultural metarepresentations spread throughout their society. These may establish in which situations or with whom it is advisable (not) to speak, keep silent or the amount of talk/silence appropriate, tolerable or expectable. When in the presence of their British counterparts, a sociopragmatic failure may arise on the part of the Finnish students because, to those interlocutors, the appropriate or expectable behaviour in such a situation would be to avoid silence. A similar thing happens with certain linguistic routines or formulae. To the Arabs reported by Nelson et al. (1996), the formula in (2) is a perfect valid candidate for the ritual of opening a conversation, whereas that formula is considered an intrusive question by their American interlocutors who did not know them:

(2) Where are you from?

When the Britons tried to engage in small talk with their Finnish interlocutors and when the Arabs resorted to the alluded formula to start a conversation with Americans, their Finnish and American interlocutors processed their behaviour guided by the expectations of relevance that their respective verbal behaviours generated. Following the relevance-theoretic comprehension procedure, they accessed their respective cultural knowledge and drew conclusions about their respective interlocutors which may not be accurate or realistic. They stop when reaching those conclusions because their expectations of relevance are satisfied, and, consequently misinterpret their interlocutors' behaviour.

In most cases, speakers are supposed to behave both competently and benevolently. Nevertheless, a lack of cultural metarepresentations or differences in the contents thereof may provoke unfortunate misunderstandings and pragmatic failures, even if speakers assume that 
their behaviour is perfectly acceptable and appropriate to the interactive context. Speakers may not be competent when interacting, however, and this is the case of many non-native speakers and learners. They may not master the L2 linguistic system or be aware of the constraints operating upon certain linguistic behaviours in specific circumstances in the target culture. In other cases, non-native speakers may not take into account some features of the interactive situation, which may favour one interpretation over another, or foresee the contexts that their interlocutors will most easily and quickly access to interpret utterances. Still, in other cases, non-native speakers may not select the most adequate wording or intonation that leads hearers to recover the interpretation they intend to communicate (Sperber 1996: 192). The linguistic incompetence of non-natives may bias their interlocutors and make them obtain unintended interpretations and hence dramatically increase the likelihood that pragmatic failure may occur. Pragmatic failure can have negative consequences because hearers, regardless of whether they are native or non-native, may arrive at interpretations that significantly differ from those that speakers might have intended to communicate. These interpretations may induce them to attribute intentions to speakers that they do not actually have. The question that now arises is how teachers can help students avoid or overcome such failures resulting from an incorrect interpretation of utterances in which hearers opt for the first interpretation that comes to mind, and, perceiving it to be optimally relevant, believe that it is the one the speaker intended to communicate.

\section{Avoiding pragmatic failure}

Practitioners in pragmatics and second language teaching have made many calls for greater efforts to raise learners' pragmatic awareness or metapragmatic abilities in formal language 
instruction (e.g. Sharwood-Smith 1981; Thomas 1983; House 1990; Olshtain and Cohen 1990, 1991; Kasper and Rose 2002). Such awareness and abilities can help both teachers and learners understand why pragmatic failure arises and find appropriate and efficient remedies. Consequently, it has been argued that teachers should prepare awareness-raising activities that stress the need and importance of activating the learners' metapragmatic knowledge involving the pragmatic development they have already undergone in their L1 (Garcés Conejos and Bou Franch 2002: 95).

Practitioners in pragmatics and second language teaching have also emphasized the need to endow students with the linguistic tools that enable them to interact in the most native-like way possible in different contexts, with the caveat that teachers should not impose any specific personality upon the students but allow them to express themselves and project the image that they would like. Teachers' praxis should not be dogmatic or prescriptive, but leave students a certain leeway so that they can make informed choices based on the interactive norms they would like to adhere to and the verbal behaviour they would like to resort to in specific situations (Kasanga 2001). As Riley (2006) points out, the ultimate goal in a realistic and ethical approach to L2 teaching should not be to clone native speakers, but to produce competent foreigners who can express themselves both efficiently and acceptably.

Many proposals and suggestions have been launched as to how to raise students' pragmatic awareness and metapragmatic abilities. Despite the shortcomings and negative influence that translation may have, Thomas (1989), House (1990) and Taha and Aqil (2004) have highlighted the benefits of translation in an L2 class as a way of filling in pragmatic gaps, developing mental schemata appropriate to the L2, and using compensatory strategies, such as paraphrase and circumlocution. Other authors have advocated the use of authentic material (films, video clips, TV and radio programmes, etc.) that guarantees learners' engagement/immersion in authentic or real cultural experiences. Other suggestions include: 
- cards to take notes on how native interlocutors behave in particular contexts,

- cultural capsules with information about interaction in specific settings,

- bringing native speakers to the classroom to share experiences, and

- role playing to interact in different contexts to achieve specific goals.

Authors also find it helpful to analyse and discuss the weight of sociological variables and cultural norms and values intervening in particular encounters and to carry out a triangulation phase in which learners and teachers examine their behaviour, decisions and possible failures. Other activities are ethnographic activities, in which students must collect data from their family, friends, classmates or acquaintances to discuss interactive behaviour and examine possible pragmatic failures, their causes and solutions. Finally, retrospective activities, in which students have to remember past situations in which they felt badly as a consequence of having been perceived in a way different from the one they would have expected. In these activities, teachers may ask them to analyse the factors that led other individuals to perceive them in that way (Holmes and Brown 1987; Olshtain and Cohen 1990, 1991; Reynolds 1995; Peterson and Coltrane 2003).

DiPietro (1987), Bardovi-Harlig et al. (1991) and Olshtain and Cohen (1991) propose that teachers should first carry out a diagnostic assessment of the level of their students' awareness of speech acts in general and of particular speech acts. In this assessment, students would have to identify frequent routine formulae in their native language used to perform a given language function, then discuss the effects of their linguistic choices and identify the L2 formulae they already know. Afterwards, teachers would present additional unknown formulae and ask students to practice them. Then, teachers would expose students to model dialogues with authentic or simulated authentic discourse, in real or simulated situations, and evaluate the situation with students. Next, students would engage in role play activities, for which they would have to rehearse what they would say in the assigned context, act out the 
situation, and explain what they did, as well as how and why they behaved in that particular way. This would be followed by a final phase of feedback, discussion and conclusion where students would talk about their perceptions or expectations, as well as point out similarities and differences between the L1 and the L2. Feedback would heighten the students' awareness of speech act behaviour and help them recognise areas of potential interference between the L1 and the L2. Through feedback, students may become aware that their participation in communicative activities may be influenced to some extent by their L1 knowledge and sociocultural expectations.

The aim of those activities is to expose learners to real contexts in which they get the feeling of working with real language and situations, for "[...] simulated exercises [cannot] provide the range of socio-pragmatic information that is readily available in authentic exchanges" (Clennell 1999: 84). With these activities, teachers can sensitise learners to when, how, where and to whom they can perform a speech act (sequence) so as to conveniently train them in their performance. Although these activities may not exhaustively cover all the possible situations that learners will find, they will certainly help L2 learners infer the mental schemata that allow them to produce and interpret authentic language (Brown 1990). Indeed, learners must certainly develop inferential skills to deduce from their L1 pragmatic knowledge or already acquired L2 pragmatic knowledge what sort of behaviour is expected in unknown or novel situations. In these activities, moreover, emphasis is not exclusively put on linguistic skills, but also on the L2 pragmatic rules/principles, background knowledge and social skills required by the L2 culture. As a result, learners achieve a similar competence to that of their native counterparts or enrich the knowledge they already possess (House 1990; Hale 1996). An excessive focus on such knowledge, however, may be somehow dangerous, as the learner can think that $\mathrm{s} / \mathrm{he}$ is a sort of non-thinking machine incapable of choice. Furthermore, an undue emphasis on pragmatic principles associated with a particular community of practice 
may make students feel they are subjected to some sort of political bias or linguistic imperialism (Kasanga 2001).

As can be seen, the activities proposed seem to be aimed at developing or improving learners' communicative competence as producers of utterances. This is most likely a consequence of the majority of the current models of communicative competence (e.g. Canale and Swain 1980; Canale 1983; Bachman 1990; Celce-Murcia et al. 1995), which revolve around the figure of the speaker and her production processes, and hence emphasise their role in communication. However, hearer and speaker roles are constantly interchanged as conversations unfold, so that interlocutors may be hearers and speakers at different moments. Garcés Conejos and Bou Franch (2002) have highlighted the importance of being a competent listener when learning and using an L2. Learners must be conscious that, as hearers, their role is not passive but active, as they bear the responsibility for interpreting messages and avoiding pragmatic failures and misunderstandings by showing that they do or do not understand correctly. Therefore, teachers must make them acquainted with certain verbal responses that are essential for a satisfactory development of interaction. Among these are:

a) affect-neutral minimal responses, such as mm, uhuh, yeah, etc.;

b) supportive minimal responses to express involvement with their interlocutor; or

c) cooperative overlaps, such as interjections, sentence completion, echoes, total or partial repetitions, etc., with which they can signal high involvement.

Additionally, in order to check whether they are on the right interpretive track, learners must acquire a certain command over comprehension checks, clarification requests, repetitions, etc. In some cases, it might be relatively easy for learners to access their knowledge of these responses, check their use in the L1 and L2, and transfer them to their interlanguage (Garcés Conejos and Bou Franch 2002: 96). Using these responses will certainly enhance communication and meaning negotiation, for learners can assist their interlocutors during 
interaction.

Nevertheless, in order to avoid pragmatic failures and misunderstandings, learners must be made aware of the importance of correctly processing and attributing intentions to other individuals. Communication is a human activity that involves mindreading, i.e. an ability to attribute beliefs and intentions to other individuals (Sperber and Wilson 1986, 1995; Sperber 1994, 1995; Wilson 1999; Wilson and Sperber 2004). It does not exclusively rely on the existence of a shared code and the encoding and decoding of messages. Communication is an ostensive-inferential activity in which the speaker produces utterances which the hearer has to decode, and, more importantly, enrich with contextual material so as to obtain propositional forms and recover implicatures. In order for the hearer to arrive at the speaker's meaning, he must use the linguistic evidence provided by the speaker as well as his cultural and contextual knowledge in order to attribute beliefs and/or intentions to the hearer. Therefore, teachers should focus on both how individuals contextualise utterances in order to reach optimally relevant interpretations and on a cognitive strategy that will help learners make correct attributions of beliefs and intentions.

\section{Focusing on hearers and understanding to overcome pragmatic failure}

If communication in a L1 involves many risks, those risks increase significantly when communicating in an L2. Pragmatic failure arises when non-native speakers unknowingly select communicative strategies that have different values in the L2 culture, or when their behaviour deviates from what individuals belonging to other communities of practice consider appropriate to certain circumstances. Such selections or deviations are interpreted by those individuals on the basis of their cultural knowledge and/or available contextual assumptions, 
which may yield unintended conclusions. On the evidence of the communicative strategy selected and behaviour deviating from conventions regarding specific circumstances, hearers may feel induced to attribute to their interlocutors underlying prefailure beliefs and intentions causing their (linguistic) behaviour, which these may not actually have (Field 2007). Hearers do so because they observe a mismatch between their interlocutors' linguistic behaviour and their own cultural metarepresentations dictating what is adequate or expectable in a particular context or because they select inadequate contextual assumptions for processing. Cultural metarepresentations encourage hearers to anticipate the way in which other individuals could or should behave or to expect a certain outcome from their behaviour in a given situation. However, non-natives' actual behaviour may not coincide with hearers' expectations and surprise or frustrate them. If this happens, hearers try to look for an explanation for the behaviour by attributing certain beliefs and intentions to their interlocutors which they believe to have informed and guided their actions (Field 2007: 134). If that attribution of beliefs and/or intentions is ill-founded, hearers may end up forming an erroneous perception of their non-native interlocutors. In fact, in many cases, it is not the non-native speaker's intention to be offensive, rude, impolite or to impose upon the native, as the natives may think.

The real problem with pragmatic failure is that an interpretation that should not have otherwise achieved an optimal level of relevance actually does so and that the hearer uses it as evidence to make attributions of beliefs and/or intentions to his interlocutor on the basis of his cultural knowledge and/or contextual assumptions. Therefore, in the L2 class, emphasis should be put on the development of a cognitive strategy that involves a greater degree of sophistication than naïve optimism and enables learners as hearers to reject apparently relevant interpretations for alternative ones that do not induce them to think that their interlocutors' intentions differ from their actual ones. This strategy is cautious optimism, “[...] a special case of competent attribution of intentions" (Sperber 1994:192). Learners must be 
trained to become cautious optimistic hearers so as to attribute to their interlocutors the intention to communicate interpretations that would have achieved an optimal level of relevance, and which they would have recovered more directly and with less cognitive effort, instead of other interpretations. As hearers, learners must accept other interpretations as the most relevant ones due to their non-native speakers' inaccurate or insufficient command of the L2, misinformed linguistic preferences, reduced cognitive abilities or different interactive principles at specific moments. Cautious optimism is necessary because non-native speakers do not often think of other ways of formulating their utterances or of behaving in ways which would enable their interlocutors to obtain, with minimal effort, the intended cognitive effects. They also do not often take into account contextual elements and factors that may favour an alternative interpretation instead of the one they wish to communicate. Cautious optimism makes it possible to overcome pragmatic failures originating from accidental relevance and accidental irrelevance of utterances and behaviours (Wilson 1999: 137).

\subsection{Overcoming pragmatic failure due to accidental relevance}

Pragmatic failure due to accidental relevance arises when the speaker's behaviour in a specific social context, her (incorrect) selection of a type of utterance or her utterance's linguistic formulation lead the hearer to an interpretation that appears to him relevant enough but is not the intended interpretation. The hearer stops at that interpretation because his expectations of relevance make him access cultural information regarding interaction in his own culture, which, along with the information conveyed by the utterance, induces him to arrive at a wrong interpretation. In other cases, those expectations do not induce him to enlarge his interpretive context by accessing contextual assumptions that would be fundamental for recovering the intended interpretation. If the hearer was naïve and optimistic, he would accept that 
interpretation which appeared relevant enough to him and identify it with the speaker's informative intention.

On the contrary, an optimistic and cautious hearer is able to overcome cases in which the speaker's selection of a communicative strategy, the linguistic formulation of her utterance, or her behaviour ostensibly but inadvertently makes him draw unexpected conclusions. He can reject the first apparently relevant interpretation which comes to mind and leads him to conclude that his interlocutor's informative intention is rather different from the one she actually has and expands his mental context by means of different contextual sources (Yus Ramos 2000) to consider an alternative interpretation. This enables him to maintain the presumption that his interlocutor is benevolent and does not want to deceive him, be impolite or rude, impose upon him, or invade his psychological sphere. However, he may still think that his interlocutor is incompetent in the L2, as she has not mastered its linguistic system and/or rules of usage. When facing ambiguous or pragmatically ambivalent utterances, or utterances that do not adjust to his cultural metarepresentations, a naïve optimistic hearer may think that his interlocutor has not behaved adequately or has been linguistically incompetent and try to find an explanation for such behaviour or incompetence, which he may find in the erroneous attribution of certain intentions and beliefs. An optimistic and cautious hearer, however, may consider an alternative interpretation because he realises that the conclusion he has reached as a result of the cultural or contextual information manifest to him or by stopping his processing at a certain point and not considering further information is unwarranted. This new interpretation makes it possible for him to still see his interlocutor as benevolent, though not fully competent, and prevents him from attributing intentions to her, which she does not really have. Cautious optimism is therefore called for to solve communication problems at both the explicit and implicit levels (Yus Ramos 1999a, 1999b). Regarding the explicit level of communication, a cautious optimistic hearer can overcome 
cases of puzzled understanding in which the high saliency of a contextual assumption induces him to construct a higher-level explicature that does not coincide with the speaker's actual attitude towards the propositional content that she communicates. Thus, a cautious optimistic hearer is able to wonder whether a previous belief he entertained (6), which makes him interpret an utterance such as (7) as a criticism, is right. If he feels that such belief is not right, he can discard it, expand his mental context and access contextual assumptions such as those in (18) that would lead him to obtain another optimally relevant interpretation of (7), whose higher-level explicature (19) would actually correspond to the attitude the speaker intends to express. To do so, he can use contextual sources such as utterance intonation, paralinguistic features, etc.

(6) Mary does not like very short skirts.

(7) You have bought a mini-skirt!

(18) a. Mary might have changed her mind about skirts.

b.Mary may like mini-skirts.

(19) [Mary is admiring/is praising/likes [the fact that I have bought a mini-skirt]].

Cautious optimism also helps a hearer obtain the intended explicatures of utterances after wrong reference assignment or disambiguation. He may sense that the reference he has assigned to some pronouns or deictics, or the way in which he has disambiguated a syntactic structure is not correct. He may realise that he has not chosen the adequate contextual information and, therefore, enlarge his context and search for the intended reference or the right sense of a sentence. In examples (8-10), if hearers are cautious and optimistic, they will enlarge their interpretive context by taking into account the physical environment manifest in order to re-assign reference to the deictic there (8), by searching for encyclopaedic assumptions about the speaker or looking in preceding discourse in order to find allusions to a beloved (9), or by accessing encyclopaedic assumptions about planes and flying (10) to arrive 
at the interpretation that their interlocutors intended.

(8) A: Leave it there! [there meaning upon the table]

[The hearer leaves a glass on a shelf]

A: Not there, but there!

(9) A: He is the one I love!

B: I didn't know you were in love with Peter!

A: Oh, no way, Susie! Bob is the one I love!

(10) Flying planes can be dangerous

Finally, a cautious and optimistic hearer is able to dismiss an unintended implicature which he has recovered as a result of having found an interpretation unsatisfactory and, guided by his expectations of relevance, having unnecessarily added contextual assumptions to his processing. He can realise that his context expansion was unjustified and is able to attribute to the speaker the intention not to communicate an implicit content that he has derived on his own. Thus, a cautious and optimistic hearer discards assumptions such as those in (12) in order to stop his processing at the explicit level and avoid looking for unintended implicatures that would lead him to interpret (11) as a request.

(11) Oh, it is cold in here!

(12) a. It is cold in this room.

b. The window is open.

c. If the window was closed, the room would be warmer.

d. My interlocutor might want me to shut the window.

As regards the implicit level of communication, cautious optimism is necessary to overcome misunderstandings arising due to a lack of contextual information that would guide the hearer to recover the expected implicatures or to overcome a wrong selection of contextual information that makes him arrive at alternative implicatures. In the former case, a cautious 
optimistic hearer who arrives at the plain question interpretation in (13) as a result of having processed his interlocutor's response in a context that does not include some crucial contextual information, may realise that it is not the desired interpretation. Feeling that the speaker might have wished to make her utterance optimally relevant under some other interpretation, he expands his mental context by adding contextual assumptions such as those in (20) which would lead him to the actual optimally relevant interpretation (21):

(13) Teacher: What time is it?

Student: 12.10 .

(20) a. I am entering the class.

b. The class begun at 12.00

c. I may have interrupted the class.

d. I would not have interrupted the class if I had been on time.

(21) The teacher may be saying that I am late.

Cases of accidental relevance in which the hearer arrives at alternative implicatures are exemplified in the many pragmalinguistic and sociopragmatic failures illustrated in the literature reviewed above. Thus, when Finnish students faced the small talk of their British colleagues (Reynolds 1995) or when Americans were greeted by Arabs with an unusual formulae (Arent 2000), the former party of each group interpreted the behaviour of their respective interlocutors on the basis of their own cultural metarepresentations. These would limit, in the case of the Finnish students, the amount of talk desirable or tolerable in certain circumstances, as well as when and with whom they could engage in small talk, and in the case of the Americans interacting with Arabs, how one should greet and be greeted, the amount of small talk permissible, and acceptable topics of discussion in small talk. Since they observed that their interlocutors' behaviour did not conform to the information contained in their metarepresentations but rather deviated from it, they concluded that their interlocutors 
assumed a degree of intimacy that did not actually exist, were too intrusive, etc. If these hearers had been cautious and optimistic, they would have realised that the conclusions they had drawn were the result of having wrongly resorted to (cultural) assumptions whose content significantly differed from that of their interlocutors.

Alternative implicatures can also be derived from pragmatically ambivalent utterances. When facing an utterance such as (22), a hearer may hesitate between a phatic and a non-phatic interpretation; if he regards the utterance as non-phatic, he may in turn hesitate between a request- or complaint-interpretation.

(22) Oh, God! I can't stand this temperature!

If the hearer is naïve and optimistic, he will engage in the relevance-theoretic comprehension procedure and will accept as optimally relevant the first interpretation that comes to mind. Hence, he may believe that his interlocutor's intention is simply to make a phatic comment about herself, find that interpretation relevant enough and stop his processing there. However, if the hearer is cautious and optimistic, he may access contextual and encyclopaedic assumptions such as those in (23), which could make him derive contextual implications and consider another interpretation as his interlocutor's informative intention (24). Thus, he can discard the phatic interpretation and opt for a request-interpretation:

(23) a. The windows are open.

b. The room is very cold.

c. There is a stove in the room.

d. Stoves heat rooms.

e. My interlocutor has seen the stove.

(24) My interlocutor wants me to switch the stove on.

Cautious and optimistic hearers may go a step further than naïve and optimistic hearers. They may wonder whether the first interpretation that comes to mind is in fact the interpretation 
that their interlocutors intended to communicate. Since they sense that speakers may be following different internalised cultural patterns of linguistic behaviour or assume that certain contextual information will also be manifest to them, they are encouraged to consider different interpretations. In this way, cautious and optimistic hearers can overcome pragmatic failures stemming from their interlocutors' linguistic or behavioural choices for particular circumstances as a result of the manifestness of certain assumptions or cultural knowledge about interaction in those circumstances. With those choices, speakers ostensibly but inadvertently communicate or favour unintended interpretations. Cautious optimism enables hearers to recover the intended interpretations because L2 learners have not taken into account certain contextual features and have formulated them in a way that favours other alternative, but equally possible, interpretations.

\subsection{Overcoming pragmatic failure due to accidental irrelevance}

Cautious optimism also makes it possible for the hearer to overcome cases of accidental irrelevance. These arise, for instance, when he thinks that the speaker is only transmitting information that is already known or when she makes a slip of the tongue (Wilson 1999). In these circumstances, a naïve and optimistic hearer would only consider the linguistic evidence of the utterance and, as a consequence of its apparently low level of informativeness or his being unable to process it, would not obtain cognitive effects that satisfy his expectations of relevance. However, a cautious and optimistic hearer notices the apparent irrelevance of an utterance and asks himself which (other) adequate interpretation the speaker could have intended to communicate so that the utterance would have achieved an optimal level of relevance.

Cautious optimism is decisive for overcoming cases of non-understanding at the explicit level 
of communication due to noise in the communicative channel, bad pronunciation, a strong accent or difficult/unfamiliar vocabulary. Instead of stopping his processing and therefore falling short of any cognitive effects, a cautious and optimistic hearer asks himself what the speaker might have meant and accesses a context that leads him to an optimally relevant interpretation. Accordingly, in the case of an utterance such as (5) in which the metalanguage renders understanding quite difficult, a cautious and optimistic hearer may search for contextual or encyclopaedic information referring to verbal communication, understanding, utterances, cognitive operations, etc., to infer what the speaker is saying:

(5) The hearer must embed the lower-level explicature of the utterance under the higherlevel explicature.

Cautious optimism may also help hearers overcome cases in which they do not recover an intended implicature but stop their processing at the explicit level. This may be the case in (15), which a naïve and optimistic hearer may interpret as phatic as a consequence of not accessing information that would yield an intended implicature.

\section{(15) You are late again today!}

A naïve and optimistic hearer may think that he is already aware of the information that (15) communicates and may conclude that it is irrelevant. That would prevent him from recovering any implicit content that his interlocutor may intend to communicate. A cautious optimistic hearer, on the other hand, would go one step further and, when faced with an apparent case of irrelevance, would expand his interpretive context to incorporate assumptions referring to arriving late to class, the starting time of class, his teacher's desire not to be interrupted when lecturing, etc. He could relate them to the assumptions made manifest by the utterance and other contextual assumptions and obtain cognitive effects that would indeed turn the utterance optimally relevant under an interpretation such as (16):

(16) Don't be late again! 
When processing utterances that a naïve optimistic hearer regards as phatic, however, a cautious optimistic hearer is also able to obtain cognitive effects regarding social relations. The relevance of phatic utterances may reside on information related to the politeness systems (Scollon and Wong-Scollon 1995) in which interaction takes place. Individuals select diverse types of phatic utterances - neutral, i.e. about the spatio-temporal setting, and personal, i.e. about the interlocutors (Laver 1974) - depending on the social relationship that they perceive, so they must have cultural metarepresentations determining the type of phatic tokens that they can resort to in specific circumstances (Padilla Cruz 2004, 2005). Accordingly, a cautious and optimistic hearer would expand his context so as to solve the apparent irrelevance of (25) in a context in which it is already manifest to him that the tie to which the utterance alludes is cute by considering contextual and cultural assumptions such as those in (26) referring to the use of a specific type of phatic utterances. That would enable him to move from an interpretation such as (27) to another such as (28):

(25) Cute tie!

(26) a. My interlocutor has made a personal comment on my tie.

b.Personal comments are frequently used when interlocutors are on close terms.

c.I have known my interlocutor for years.

d.My interlocutor and I have the same status.

e.My interlocutor may think that we have a solidarity relationship.

(27) My interlocutor is willing to communicate with me.

(28) My interlocutor may wish to maintain a solidarity relationship with me.

The speaker's informative intention may be rather diffuse or difficult to pin down in some communicative circumstances, so it is the hearer's task to make an attribution thereof as exact as possible. The speaker may also make weakly manifest ${ }^{7}$ some of the assumptions

\footnotetext{
${ }^{7}$ Assumptions are weakly communicated when the speaker makes less manifest her intention that the hearer uses them in his inferential processes (Sperber and Wilson 1986, 1995).
} 
constituting her informative intention and expect the hearer to use them in order to get the intended interpretation of her utterance, but the hearer may not use them or may access some other assumptions on his own and, consequently, misunderstand her utterance. When facing a case of accidental irrelevance, an optimistic and cautious hearer is able to incorporate cultural and contextual assumptions into his interpretative context, which allow him to obtain the cognitive effects that the speaker might have intended to generate.

\section{Conclusion}

Intentional communication not only presupposes the existence of an informative intention in one of the interlocutors, but also the existence of an intention that the other individual recognises that first intention (Sperber and Wilson 1986, 1995; Sperber 1994, 1995; Wilson 1999; Wilson and Sperber 2004). In order to do so, the hearer must carry out an inferential process in which he takes the speaker's informative intention as a premise and comes to a conclusion about that intention. Communication requires a certain amount of mindreading for which the hearer must resort to contextual and cultural information manifest to him in order to attribute the intention to communicate a particular content to the speaker. If a hearer assumes that his interlocutor is competent and benevolent, he will simply arrive at an interpretation that he considers relevant, attribute the intention to communicate it to his interlocutor and believe it to be her informative intention. Unfortunately, as in the case of non-native speakers, speakers are not always (fully) competent and make mistakes, so hearers must bear in mind that "Incompetence produces accidental misinformation; i.e. mistakes [...]" (Mascaro and Sperber 2009: 367).

This paper has focused on the hearer and the crucial role he plays in understanding. He is to 
some extent responsible for pragmatic failure and cautious optimism (Sperber 1994) is a useful cognitive strategy that enables the hearer to engage in a further inferential process after having realised (i) that his interlocutor is not fully competent and (ii) that the interpretation of an utterance that he finds relevant enough is not the interpretation that his interlocutor might have intended to communicate. Accordingly, as hearers, learners should be ready to search for alternative interpretations of utterances that are indeed optimally relevant and correspond to the interpretations their interlocutors intended to communicate. Cautious optimistic hearers are able to reject conclusions that optimistic and naïve hearers would draw and consider different interpretations. Therefore, teachers should make learners aware of this strategy because it significantly contributes to solve pragmatic failures and misunderstandings originating from (non-native) interlocutors' incompetence.

One of the benefits of cautious optimism is that it enables learners to avoid attributing to their interlocutors virtual prefailure beliefs or intentions that would have allegedly motivated their (verbal) behaviour and could prompt them into an erroneous appraisal of the other individual's personality. When training learners to be cautious and optimistic, teachers can help them understand that they should not look for alleged beliefs or intentions that may guide their interlocutors' linguistic behaviour, but that their behaviour obeys different cultural patterns in some cases while in others it is the result of an uninformed or wrong habit, which may lead to consequences they could be unaware of. Cautious optimism, therefore, will significantly contribute to the development or improvement of learners' epistemic vigilance, a necessary critical attention to the believability and reliability of communication (Mascaro and Sperber 2009). Such critical attention is fundamental in intercultural contexts where interlocutors are not fully competent in their L2, are unaware of L2 interactive principles or behave guided by their L1. In these contexts, the development of cautious optimism may also contribute to the avoidance or reduction of what Fricker (2007) refers to as epistemic 
injustices, which some speakers may potentially suffer if their hearers perceive that they are less-competent-than-desired knowers of their L2.

By suggesting that learners should be trained to be cautious optimistic hearers, this paper endorses the opinion that the level of learners' sophistication in understanding is not the same as that of natives (Garcés Conejos and Bou Franch 2002: 88). One of the questions that arise is how teachers can train students to become cautious optimistic hearers. Obviously, some of the activities mentioned above (Section 4) can be useful. Thus, teachers could use authentic materials showing examples of misunderstandings with more or less serious repercussions, retrospective activities in which learners remember past experiences of misunderstandings, role plays where they are put under pragmatic pressure or ask the students to act as ethnographers supplying their own examples of misunderstandings gathered from friends, acquaintances, family, relatives, etc. These activities would be followed by analyses of what made them or the people involved arrive at undesired interpretations. Thus, teachers would draw their learners' attention to the complexity and risks of intercultural communication and the learners could develop their metacognitive abilities.

Additionally, there are other questions that future research should address. Evidently, one of the first things that needs investigating is whether all types of learners are able to transfer directly cautious optimism into their L2 pragmatics or if they would actually require some training (cf. Kasper and Rose 2002). If learners transfer cautious optimism from their L1 pragmatics, it might be interesting to determine if they do so since the very beginning of their L2 learning process or, if not, at which stage they transfer it. Another factor for study would be if their age is a key factor. Likewise, it might also be illuminating to examine if they resort to this cognitive strategy in a wide variety of situations liable to misunderstandings or if the situations where they resort to it are very specific. If it were shown that learners do not transfer cautious optimism from their L1 pragmatics, it might be useful to analyse if they may 
end up becoming cautious and optimistic hearers in an autonomous way or if they need explicit and specific instruction to develop this cognitive strategy (cf. Little, Ridley and Ushioda 2003; Little 2009).

Citron (1995) contends that motivation, understood as a positive attitude towards a target language, its culture and speakers, could result in openness regarding contrasting cultural and linguistic patterns. Social and psychological factors such as tolerance for ambiguity and ego permeability could also enhance performance in an L2 by enabling the non-native to listen more attentively, process a higher amount of input or achieve a more native-like pronunciation. Finally, acculturation, understood as openness to differing cultural and linguistic patterns, also facilitates language learning, for learners seem to improve their L2 skills when they weaken their ethno-lingual ties to their own culture and are open to other cultural and linguistic expressions. It would be interesting to investigate if learners are more or less prone to misunderstand utterances or behaviour that to a higher or lesser extent differ from those they would expect in their culture/language as a consequence of a differing degree of motivation, tolerance for ambiguity, ego permeability or acculturation. It would also be interesting to see if such factors condition learners' processing skills or the selection of different processing strategies, or if cautious optimism positively develops as learners' motivation, tolerance for ambiguity, ego permeability or acculturation increase.

Understanding motivation as a self-system in which the individual or the learner is affected by future self-guides (Dörnyei 2009; Ushioda and Dörnyei 2009), it could also be rather illuminating to analyse if L2 learners' ideal and ought-to self have a significant influence on the development or selection of cautious optimism. It might be useful to examine if a learner's ideal and ought-to selves include images of the person reaching a standard of comprehension similar or close to that of native speakers or portray him/her as a fairly competent or sophisticated hearer/listener, and, if so, to what extent those images provide incentive, 
direction and impetus for developing or resorting to cautious optimism once the learner perceives a discrepancy between his/her actual self as a hearer/listener and those two other selves. By focussing on these issues, researchers will need to adopt a person-in-context relational view of motivation (Ushioda 2009), which centres on learners as real persons with an identity, personality, unique history and, more importantly, goals, motives and intentions, among which may be becoming more competent or skilful L2 hearers/listeners. Research in that direction will certainly provide new insights into learners' performance as L2 hearers, and will undoubtedly enhance L2 instruction.

mpadillacruz@us.es

University of Seville

\section{References}

Arent, Russell E. 2000. Understanding misunderstanding in the Ammani bargaining event: Pragmatic failure or instrumental rudeness? Disarat, Human and Social Sciences 27. 222243.

Bachman, Lyle F. 1990. Fundamental considerations in language testing. Oxford: Oxford University Press.

Bardovi-Harlig, Kathleen, B. A. S. Hartford, R. Mahan-Taylor, M. J. Morgan \& D. W. Reynolds. 1991. Developing pragmatic awareness: Closing the conversation. ELT Journal 45(1). 4-15.

Beebe, Leslie M. \& Tomoko Takahashi. 1989. Do you have the bag? Social status and patterned variation in second language acquisition. In Susan Gass, Carolyn Madden, 
Dennis Preston \& Larry Selinker (eds.), Variation in second language acquisition (Vol. 1: Discourse and pragmatics), 103-125. Clevedon: Multilingual Matters.

Beebe, Leslie M., Tomoko Takahashi \& Robin Uliss-Weltz. 1990. Pragmatic transfer in ESL refusals. In Robin Scarcella, Elaine Andersen \& Stephen D. Krashen (eds.), Developing communicative competence in a second language, 55-71. Rowley: Newbury House.

Blum-Kulka, Shoshana. 1988. Interpreting and performing speech acts in a second language: A cross-cultural study of Hebrew and English. In Nessa Wolfson \& Elliot Judd (eds.), Sociolinguistics and language acquisition, 36-55. Rowley: Newbury House.

Blum-Kulka, Shoshana \& Elite Olshtain. 1986. Too many words: Length of utterance and pragmatic failure. Studies in Second Language Acquisition 8(2). 165-180.

Blum-Kulka, Shoshana \& Edward A. Levenston. 1987. Lexical-grammatical pragmatic indicators. Studies in Second Language Acquisition 9(2). 155-170.

Brown, Gillian. 1990. Cultural values: The interpretation of discourse. ELT Journal 44(1). 1117.

Brown, Gillian. 1995. Speakers, listeners and communication. Explorations in discourse analysis. Cambridge: Cambridge University Press.

Canale, Michael. 1983. From communicative competence to communicative language pedagogy. In Jack C. Richards \& Richard W. Schmidt (eds.), Language and communication, 2-28. London: Longman.

Canale, Michael \& Merril Swain. 1980. Theoretical bases of communicative approaches to second language teaching and testing. Applied Linguistics 1(1). 1-47.

Celce-Murcia, Marianne, Zoltán Dörnyei \& Sarah Thurrell. 1995. Communicative competence: A pedagogically motivated model with content specifications. Issues in Applied Linguistics 6(2). 5-35.

Chen, Rong. 1993. Responding to compliments. A contrastive study of politeness strategies 
between American English and Chinese speakers. Journal of Pragmatics 20(1). 49-75.

Citron, James L. 1995. Can cross-cultural understanding aid second language acquisition? Toward a theory of ethno-lingual relativity. Hispania 78. 105-113.

Clennell, Charles. 1999. Promoting pragmatic awareness and spoken discourse skills with EAP classes. ELT Journal 53(2). 83-91.

Coupland, Justine, Nikolas Coupland \& Jeffrey D. Robinson. 1992. How are you? Negotiating phatic communion. Language in Society 21(2). 207-230.

Dörnyei, Zoltán. 2009. The L2 motivational self-system. In Zoltán Dörnyei \& Ema Ushioda (eds.), Motivation, language identity and the L2 self, 9-42. Bristol: Multilingual Matters.

Eisenstein, Miriam \& Jean Bodman. 1993. Expressing gratitude in American English. In Gabriele Kasper \& Shoshana Blum-Kulka (eds.), Interlanguage pragmatics, 64-81. New York: Oxford University Press.

Escandell Vidal, María Victoria. 1996. Towards a cognitive approach to politeness. Language Sciences 18. 629-650.

Færch, Claus \& Gabriele Kasper. 1989. Internal and external modification in interlanguage request realisation. In Juliane House, Shoshana Blum-Kulka \& Gabriele Kasper (eds.), Cross-cultural pragmatics: Requests and apologies, 221-247. Norwood: Ablex.

Field, Richard W. 2007. Pragmatic failure and the attribution of belief. Journal of Philosophical Research 32. 133-143.

Flowerdew, Lynne. 1997. Interpersonal strategies: Investigating interlanguage corpora. RELC: Journal of Language Teaching and Research 28(1). 72-88.

Fricker, Miranda. 2007. Epistemic injustice. Power \& the ethics of knowing. Oxford: Oxford University Press.

Garcés Conejos, Pilar \& Patricia Bou Franch. 2002. A pragmatic account of listenership: Implications for foreign/second language teaching. Revista Alicantina de Estudios 
Ingleses 15. 81-102.

García, Carmen. 1989. Apologising in English - Politeness strategies used by native and nonnative speakers. Multilingua 8(1). 3-20.

Hale, Sandra. 1996. Pragmatic considerations in court interpreting. Australian Review of Applied Linguistics 19. 61-72.

Han, Chung-hye. 1992. A comparative study of compliment responses: Korean females in Korean interactions and in English interactions. Working Papers in Educational Linguistics 8(2). 17-31.

Harlow, Linda L. 1990. Do they mean what they say? Sociopragmatic competence and second language learners. The Modern Language Journal 74(3). 328-351.

Hayashi, Takuo. 1996. Politeness in conflict management: A conversation analysis of dispreferred message from a cognitive perspective. Journal of Pragmatics 25(2). 227-255.

Hickey, Leo. 1991. Comparatively polite people in Britain and Spain. ACIS: Journal of the Association for Contemporary Iberian Studies 4(2). 2-6.

Holmes, Janet \& Dorothy Brown. 1987. Teachers and students learning about compliments. TESOL Quarterly 21(3). 523-546.

House, Juliane. 1990. Cross-cultural pragmatic failure: From mistranslation to misunderstanding. In Reiner Arntz and Gisela Thome (eds.), Übersetzungswissenchaft: Ergebnisse und Perspectiven. Festschrift für Wolfram Wilss, 315-325. Tübingen: Narr.

Hurley, Daniel S. 1992. Issues in teaching pragmatics, prosody, and non-verbal communication. Applied Linguistics 13(3). 259-281.

Jaworski, Adam. 1994. Pragmatic failure in a second language: Greeting responses in English by Polish students. International Review of Applied Linguistics in Language Teaching 32(1). 41-55.

Kakavá, Christina. 1993. Conflicting argumentative strategies in the classroom. In James E. 
Alatis (ed.), Georgetown University Roundtable on Languages and Linguistics (GURT) 1993. Strategic interaction and language acquisition: Theory, practice, and research, 402-420. Washington, DC: Georgetown University Press.

Kasanga, Luanga A. 1998. Requests in English by second language users. ITL, Review of Applied Linguistics 119-120. 123-153.

Kasanga, Luanga A. 2001. Intercultural sociolinguistics and communication research in South Africa: Its relevance to academic settings and the service industry. Southern African Linguistics and Applied Language Studies 19. 253-273.

Kasanga, Luanga A. \& Joy-Christine Lwanga-Lumu. 2007. Cross-cultural linguistic realisation of politeness: A study of apologies in English and Setswana. Journal of Politeness Research 3(1). 65-92.

Kasper, Gabriele. 1984. Pragmatic comprehension in learner-native speaker discourse. Language Learning 34(4). 1-20.

Kasper, Gabriele. 1992. Pragmatic transfer. Second Language Research 8(3). 203-231.

Kasper, Gabriele \& Shoshana Blum-Kulka (eds.). 1993. Interlanguage pragmatics. New York: Oxford University Press.

Kasper, Gabriele \& Kenneth R. Rose. 2002. Pragmatic development in a second language. Malden, MA: Blackwell.

Kwon, Jihyun. 2004. Expressing refusals in Korean and in American English. Multilingua 23(4). 339-364.

Laver, John. 1974. Communicative functions of phatic communion. Work in Progress 7. 1-17. Leech, Geoffrey. 1983. Principles of pragmatics. London: Longman.

Little, David G. 2009. Language learner autonomy and the European Language Portfolio: Two L2 English examples. Language Teaching 42(2). 222-233.

Little, David G., Jennifer Ridley \& Ema Ushioda (eds.). 2003. Language autonomy in the 
foreign language classroom: Teacher, learner, curriculum and assessment. Dublin: Authentik.

Long, Donna R. 1989. Second language listening comprehension: A schema-theoretic perspective. Modern Language Journal 73. 32-40.

Lwanga-Lumu, Joy-Christine. 2002. Internal request modification by first and second language speakers. Tydskrif vir Taalonderrig [Journal for Language Teaching] 36(3-4). 289-304.

Mascaro, Olivier \& Dan Sperber. 2009. The moral, epistemic, and mindreading components of children's vigilance towards deception. Cognition 112(3). 367-380.

Nelson, Gayle L., Mahmoud Al-Batal \& Erin Echols. 1996. Arabic and English compliment responses: Potential for pragmatic failure. Applied Linguistics 17(4). 411-432.

Nelson, Gayle L., Waguida El Bakary \& Mahmoud Al Batal. 1996. Egyptian and American compliments: Focus on second language learners. In Susan M. Gass \& Joyce Neu (eds.), Speech acts across cultures. Challenges to communication in a second language, 109128. Berlin: Mouton de Gruyter.

Olshtain, Elite. 1983. Sociocultural competence and language transfer: The case of apology. In Stephen D. Krashen \& Robin C. Scarcella (eds.), Series on issues on second language research, 232-249. Rowley: Newbury House.

Olshtain, Elite \& Andrew D. Cohen. 1989. Speech act behaviour across languages. In Hans W. Dechert \& Manfred Raupach (eds.), Transfer in language production, 53-67. Norwood: Ablex.

Olshtain, Elite \& Andrew D. Cohen. 1990. The learning of complex speech act behaviour. TESL Canada Journal 7(2). 45-65.

Olshtain, Elite \& Andrew D. Cohen. 1991. Teaching speech act behaviour to nonnative speakers. In Marianne Celce-Murcia (ed.), Teaching English as a second or foreign 
language, 154-165. New York: Newbury House.

Padilla Cruz, Manuel. 2004. Aproximación pragmática a los enunciados fáticos. Enfoque social y cognitivo. Sevilla: Universidad de Sevilla.

Padilla Cruz, Manuel. 2005. On the phatic interpretation of utterances: A complementary relevance-theoretic approach. Revista Alicantina de Estudios Ingleses 18. 227-246.

Pennock, Barry \& Francisca Suau. 1998. Text coherence and pragmatic failure. Quaderns de Filologia: Estudis Lingüístics 4(3). 105-121.

Peterson, Elizabeth \& Bronwyn Coltrane. 2003. Culture in second language teaching. CAL Online Resources: Digests. http://www.cal.org/resources/digest/0309peterson.html (accesed 15 March 2009).

Reynolds, Mike. 1995. Where the trouble lies: Cross-cultural pragmatics and miscommunication. Papers and Studies in Contrastive Linguistics 30. 5-15.

Riley, Philip. 1989. Well don't blame me! On the interpretation of pragmatic errors. In Wieslaw Oleksy (ed.), Contrastive pragmatics, 231-249. Amsterdam: John Benjamins.

Riley, Philip. 2006. Self-expression and the negotiation of identity in a foreign language. International Journal of Applied Linguistics 16(3). 295-318.

Scollon, Ron \& Suzanne Wong-Scollon. 1995. Intercultural communication. A discourse approach. Cambridge: Blackwell.

Shakir, Abdullah \& Mohammad Farghal. 1991. The activation of schemata in relation to background knowledge and markedness. Text 11(2). 201-211.

Sharwood-Smith, Michael. 1981. Consciousness-raising and the second language learner. Applied Linguistics 2(2). 159-168.

Sperber, Dan. 1994. Understanding verbal understanding. In Jean Khalfa (ed.), What is intelligence?, 179-198. Cambridge: Cambridge University Press.

Sperber, Dan. 1995. How do we communicate? In John Brockman \& Katinka Matson (eds.), 
How things are: A science toolkit for the mind, 191-199. New York: Morrow.

Sperber, Dan. 1996. Explaining culture. A naturalistic approach. Oxford: Blackwell.

Sperber, Dan \& Deirdre Wilson. 1986. Relevance. Communication and cognition. Oxford: Blackwell Publishers.

Sperber, Dan \& Deirdre Wilson. 1995. Relevance. Communication and cognition. $2^{\text {nd }}$ edn. Oxford: Blackwell Publishers.

Taha, Fayez M. \& Fawwaz M. T. Aqil. 2004. Using translation as a means of overcoming cross-cultural pragmatic failure. International Journal of Arabic-English Studies 5. 189198.

Takahashi, Tomoko \& Leslie M. Beebe. 1987. The development of pragmatic competence by Japanese learners of English. JALT Journal 8. 131-155.

Takahashi, Tomoko \& Leslie M. Beebe. 1993. Cross-linguistic influence in the speech act of correction. In Gabriele Kasper \& Shoshana Blum-Kulka (eds.), Interlanguage pragmatics, 138-158. New York: Oxford University Press.

Tannen, Deborah. 1984. The pragmatics of cross-cultural communication. Applied Linguistics 5(3). 188-195.

Tannen, Deborah. 1990. You just don't understand. Women and men in conversation. London: Virago Press.

Thomas, Jenny. 1983. Cross-cultural pragmatic failure. Applied Linguistics 4(2). 91-112.

Thomas, Stephen. 1989. Using translation to overcome cross-cultural pragmatic failure. New Comparison: A Journal of Comparative and General Literary Studies 8. 75-84.

Tran, Giao Q. 2006. The nature and conditions of pragmatic and discourse transfer investigated through naturalized role-play. Muenchen: Lincom.

Ushioda, Ema. 2009. A person-in-context relational view of emergent motivation, self and identity. In Zoltán Dörnyei \& Ema Ushioda (eds.), Motivation, language identity and the 
L2 self, 215-228. Bristol: Multilingual Matters.

Ushioda, Ema \& Zoltán Dörnyei. 2009. Motivation, language identities and the L2 self: A theoretical overview. In Zoltán Dörnyei \& Ema Ushioda (eds.), Motivation, language identity and the L2 self, 1-8. Bristol: Multilingual Matters.

Wenger, Etienne. 1998. Communities of practice. Learning, meaning and identity. Cambridge: Cambridge University Press.

Wilson, Deirdre. 1999. Metarepresentation in linguistic communication. UCL Working Papers in Linguistics 11. 127-161.

Wilson, Deirdre \& Dan Sperber. 2004. Relevance theory. In Laurence Horn \& Gregory Ward (eds.), The handbook of pragmatics, 607-632. Oxford: Blackwell.

Wolfson, Nessa. 1989. Perspectives: Sociolinguistics and TESOL. New York: Newbury House.

Yus Ramos, Francisco. 1999a. Towards a pragmatic taxonomy of misunderstandings. Revista Canaria de Estudios Ingleses 38. 217-239.

Yus Ramos, Francisco. 1999b. Misunderstandings and explicit/implicit communication. Pragmatics 9(4). 487-517.

Yus Ramos, Francisco. 2000. On reaching the intended ironic interpretation. International Journal of Communication 10(1-2). 27-78.

Žegarac, Vladimir. 1998. What is phatic communication? In Villy Rouchota \& Andreas H. Jucker (eds.), Current issues in relevance theory, 327-361. Amsterdam: John Benjamins. Žegarac, Vladimir. 2009. A cognitive pragmatic perspective on communication and culture. In Helen D. Spencer-Oatey \& Peter Franklin (eds.), Intercultural interaction: A multidisciplinary approach to intercultural communication, 31-53. Basingstoke: Palgrave. 